\title{
Wine and Interaction Design
}

\author{
Jeni Paay, Toni Robertson, Margot Brereton, Yvonne Rogers \\ Affiliation \\ Address \\ e-mail address \\ Optional phone number
}

\begin{abstract}
Wine and Interaction Design presents an interesting opportunity to the HCI community, as technology plays an increasing role in the many facets of wine production and consumption. People interact with technology in all phases of the wine lifecycle, including the grape growing process, harvesting the grapes, supporting the winemaking process, labelling the wine, wine selling, and wine serving.

Inspired by the CHI 2012 workshop on Food and Interaction Design (Comber et al., 2012), this workshop will bring together HCI researchers and practitioners with an interest in the the role that interaction design and technology can play in wine production and consumption. The session will include discussions on issues and topics of interest raised in position papers contributed by participants. During a practical field visit the workshop will engage with local Tasmanian wine producers to understand and explore current wine-based practices using technology.
\end{abstract}

The outcome of the workshop will be the identification of new opportunities for HCI researchers and practitioners to forge a synergy between technology and wine.

\section{Author Keywords}

Wine, Interaction Design, HCI, Ubiquitous Computing

\section{ACM Classification Keywords}

H5.m. Information interfaces and presentation (e.g., HCI): Miscellaneous.

\section{INTRODUCTION}

Wine is a simple word for a complex commodity. The wine industry is an important part of the Australian economy and the Australian experience. The Australian wine sector contributes $\$ 40.2$ billion to national economy. The total in bottled wine exports for the past year was $\$ 2.1$ billion (wineaustralia.com). Domestic sales of wine per year are usually around $\$ 2.5$ billion (abs.gov.au), so Australians do enjoy Australian wines, as much as the rest of the world does. Australia is a special producer of wine because it is such a large country that almost every climate and soil type Permission to make digital or hard copies of all or part of this work for personal or classroom use is granted without fee provided that copies are not made or distributed for profit or commercial advantage and that copies bear this notice and the full citation on the first page. Copyrights for components of this work owned by others than ACM must be honored. Abstracting with credit is permitted. To copy otherwise, or republish, to post on servers or to redistribute to lists, requires prior specific permission and/or a fee. Request permissions from Permissions@acm.org.

OzCHI '16, November 29 - December 2 2016, Launceston, TAS, Australia

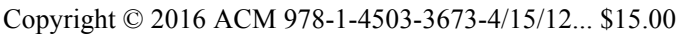

http://dx.doi.org/xx.xxxx/xxxxxxx.xxxxxxx.

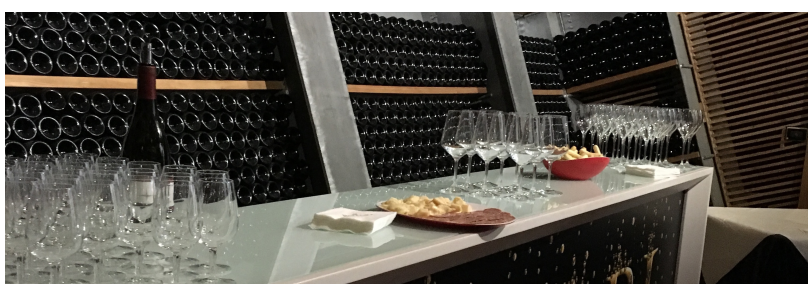

can be found, with a vast array of different grape varieties being grown. This means that all major wine types are produced in Australia, including red, white, fortified and sparking. Australia also has some of the oldest grape vines in the world. Many of Europe's established vineyards were destroyed by disease in the 1800 s with the only survivors being the vines brought to Australia. In order to preserve these, Australian viticulturists have developed some of the vine management techniques now used throughout the world. Australian winemakers have also invented ways to produce wines with fewer chemicals (Australia.gov.au). Wine and wine making are of interest to many disciplines, including economics, marketing, history, education, agriculture, biology, chemistry, health, sustainability, engineering, sociology, industrial design and computer science. In this workshop, we would like to focus on the challenges for HCI, and given the multi-disciplinary nature of HCI research, this will likely involve related research from other disciplines.

We would like to look at new opportunities for the wine industry, given recent advances in technology that allow computing to move off the desktop and into the world around us. As ubiquitous computing moves on from Weiser's vision of calm computing (Rogers, 2006), the new agenda for UbiComp becomes moving beyond tools, devices and systems to engaging people in their activities and pursuits, for example, working out the best time to spray or pick grapes in a vineyard. This move has also resulted in innovative ways to re-excite peoples interest in interacting with technology in their environments, enabling inquiries and decision making to be done in situ, in places such as the vineyard, the winery, the wine shop or the wine bar. The places of wine production and consumption provide environments where UbiComp can enable people to be smarter, more proactive, and more exploratory in their work and everyday practices.

This workshop will bring together HCI researchers and practitioners, with knowledge and experience, to view the current relationship between technology and wine, and bring different viewpoints into a discussion on theories, methods, designs, or empirical studies, that can help us to explore and identify new opportunities for technology and interaction design with wine. 


\section{RELATED RESEARCH}

There is limited research and practice in HCI literature that directly relates to wine and vineyards. Some have worked on sensor networks in the vineyard and worker interaction with these. However, there is related food HCI research which can inspire the way we approach wine HCI research.

\section{UbiComp in the Vineyard}

A highly published study in this area is one initiated at Intel Research, to explore the potential for ubiquitous computing systems in the vineyard (Burrell et al., 2003; Brooke and Burrell, 2003; Burrell et al., 2004). In related papers, the authors describe how an ethnographic process, conducted over several months looked into the work roles and grape growing activities in a vineyard. This ethnography was then used to inspire interaction design for a ubiquitous computing system. This research was part of ongoing work exploring the potential for ubiquitous computing systems in agricultural and outdoor environments. The initial brief of the project was to explore how ubiquitous computing, in particular sensor network technology, could be useful to the wine industry.

Using design ethnography and the design process outlined by cognitive ethnography, the team designed a network of sensors for monitoring the microclimate of a vineyard, as managing that microclimate can directly influence the quality of the harvest, and hence the wine produced. Fieldwork involved a combination of semi-structured interviews and participant observation, across the whole spectrum of wine production, from vineyard managers to wine sellers. The design team then generated design solutions for many of the issues and opportunities they discovered through the ethnography. They were able to go beyond concept development for some of the design ideas generated and to prototype technology with interfaces that were deployed in the vineyard. They were able to measure temperatures at different points in the vineyard to show how the microclimate varied to the vineyard manager. Through these designs, the team was able to show potential ways of adding value to wine production through the deployment of a sensor network into the vineyard.

In Burrel et al. (2004) they show that designing a pervasive computing system to support workers in a vineyard differs significantly from designing for an office environment. The technologies in a vineyard need to have a strong tie to the physical and varied environments as well as physical, tool-based activities. In addition to this, the different roles of the workers mean that they require access to different kinds of information, while completing very different work tasks. This means a variety of interfaces and entry points for interacting with the system. Further work from Intel (Sherry et al., 2004) concluded that in non-office work environments, such as the vineyard, it is important for ubicomp systems to align with the different agendas and different communication needs of workers.

Another research project in a vineyard (Kameoke at al., 2014), provided climate and soil moisture measurement using a wireless sensor network for viticultural management. They also provided sap flow sensing and image measurement of grape berry colours. This was a technical exploration of sensor networking capabilities in an outdoor environment, measuring viticulture specific data. While their focus was on making the environment smart, they also support the importance of a user interface that shows only information that is relevant, timely and comprehensive in supporting decision making.

\section{Sociality and Food}

In addition to the specific research on wine and vineyards, related studies on food interaction and commensality (O'Hara et al. 2012) have issues of sharing and social connection which are equally applicable to sharing a bottle of wine with family and friends. Instead of photos as mementos, perhaps the wine labels embedded with sensors, or wine memories captured by technology could become the shared personal items and focal point for social interaction.

Wine as part of a social gathering can play several roles. Like food, it is something that can bring people together, where people interact through and around the sharing of wine. Just as Grimes and Harper talk about food (2008), it is important to understand the role that technology currently plays in wine production and consumption and the roles it can be imagined to play in the future. Maybe our aim as interaction designers should be to look at human-wine-computer interaction in terms of designing "celebratory technology" that enhances the positive interactions that people have with wine as they share it with others.

\section{RELATED PRACTICE}

While there is limited wine-related HCI research, there is much more happening in practice. There are many designs out there, from winery museums through labelling of wine bottles coupled with information apps to enhancing the wine tasting experience. Most of this work focusses on providing wine consumers with more information about the provenance and qualities of wine, as a way to enhance the wine drinking experience. More interestingly, some designers are working to enhance the experience using colour, texture and music to celebrate the moment of that first sip.

\section{Providing the bigger picture}

Strukt (strukt.com) is a company that creates digital media experiences. They have worked with the wine industry to create designs for information terminals and installations giving visitors a tour to experience wine in the form of an exhibition. They have also created a concept design for a wine museum which guides users through a winery while delivering stories on an iPod. The stories can take place in the past, present or future, and all revolve around the fascination of wine. The stories were envisioned as being anything from criminal or adventure stories to biographical and documentary narratives. The system is designed to be location-based and respond to the user's location with relevant content and navigational guidance.

Wine labelling is an area where technology is also being used to tell a more of the story. The iQ-dio Interactive Labels company (iqdio.com) claims to have designed the next generation of wine labels. They produce interactive labels for smartphone enabled customers, where the producers or distributers can gain access to data about 
when and where shoppers pick up their bottles of wine. The labels use dynamic QR coding which has the dual purpose of providing information about the wine to the users, and providing tracking data to the wine maker. The information delivered to consumers includes an instant audio message from the winemaker describing the wine along with links to tasting notes, food pairings and more. It does this without the need to download an app. They also give the winemakers a web portal that guides them through content creation and modification, which become immediately available to consumers through the QR code already on the bottle.

Another take on the interactive wine shopping experience was created as a project design by an interaction design student team in the IXDA 2015 competition (xinlilin.com). Their design aimed to augment the in-store shopping experience to compete with online wine vendors. They did this by increasing the physical interaction with wine bottles when shopping. Using an interactive surface, customers can take a bottle of wine they are interested in, place it on the surface and get additional information, beyond what can be placed on the limited space of a wine label, to help them choose which wine to buy.

\section{Making wine individual}

While drawing your own design on a wine label is interactive, when you share it online, you communicate it with others. On June 18, 2014, the LA Times reported on a new idea in wine labelling. They called it the world's first interactive wine label. The concept is that the label, called the "scratchpad" is designed with free space on it, and a pencil is provided around the bottle neck. This is to encourage people to draw on the label and then share their creation using social media. The label company manages a Facebook page dedicated to sharing these labels.

\section{Tasting with Technology}

To reinvent the wine tasting experience, Potion Design created an interactive wine bar for the Clo Bar in New York (potiondesign.com). This design gives patrons the opportunity to be their own sommelier and pour their own wine. This is achieved with a 20 -foot long interactive communal table which acts as both a menu and a guide, giving detailed sommelier notes, wine prices, and a map of their own personalized tasting. They then use a prefilled purchase card to buy a glass of the selected wine from wine dispensers located around the perimeter of the space. The table is implemented using ceiling projection and motionand light-sensor technology to enable natural user interaction with information about the wines available.

A similar installation is found at the Adour bar at St. Regis hotel in New York, also designed by Potion Design (salvadororara.com). A four seat wine bar provides an interactive wine list, from which customers can make their wine selection using tasting notes that appear on the bar surface. A sommelier then pours the wine. The patrons of the bar can compare the details of several wines before selecting which bottle to buy. The experience is subtle and aesthetic based on colours that reflect the deep red hues of wine, using bronze and goat skin on the sculpted bar for texture. The bar is described by its designers as "a rich interactive experience that feels lovingly crafted and as far away from technology as possible." This installation uses the same technology set up as the Clo Bar, but with more intimate sized tables.

For a more domestic and personal wine experience, Emmy Hacker (emilyhackerdesign.com) offers an interactive design of a radio that creates a more meaningful emotional interaction where the music is controlled by wine choice. A 4-bottle wine rack is embedded into the radio, and glasses and decanter sit on top. Pouring wine causes a musical response in either volume or tuning, certain bottles cause certain music genres to play, decanting the wine changes channels, and the volume depends on the number of glasses filled. According to Emmy, "This radio enhances the experience of pouring and enjoying a glass of wine by pairing it with music."

\section{WORKSHOP STRUCTURE}

This is a one-day workshop bringing together HCI researchers and interaction design practitioners with an interest in technology and the wine industry. The workshop invites a 1-3 page position paper from 10-25 workshop participants representing different aspects and areas of interest in this topic. A full day field visit and workshop will combine participant presentations interleaved with discussions with local wine makers, visiting vineyards and wine making facilities to experience the context for design, studying current labelling and information dissemination practices, and conducting contextual interviews and observations with cellar door visitors to learn their interests in and experiences of wine.

At the end of the workshop, we will discuss appropriate design methods and new research and design ideas to extend the role of interaction design in the wine industry, both in terms of support for wine production practices, and in enhancing the user experience of wine. The outcome of the workshop will be the identification of new opportunities for HCI researchers and practitioners to forge a synergy between technology and wine.

\section{Schedule of Activities:}

10:00 Bus departs city depot, Launceston

10:30 West Tamar Wineries and Vendors/Bus Talks

12:30 Lunch at Pipers Brook (TBC)

13:30 East Tamar Wineries and Vendors/ Bus Talks

16:00 Discussion and Summaries at UTas campus

17:00 Bus returns to depot in city

\section{ORGANISERS}

Jeni Paay is Associate Professor in the Research Centre for Socio-Interactive Design at Aalborg University in Denmark. Jeni likes to drink Champagne - especially pink.

Toni Robertson is Professor of Interaction Design, University of Technology, Sydney. Toni has an impressive wine cellar under her house.

Margot Brereton is Professor in Computer Human Interaction at Queensland University of Technology, Brisbane. Margot likes to drink wine while camping.

Yvonne Rogers is Professor of Interaction Design at University College London, UK. Yvonne likes to drink wine all over the world, but especially with friends. 


\section{CALL FOR PARTICIPATION}

This one-day workshop will be held as part of OZCHI 2016, in Launceston Tasmania.

This workshop will bring together HCI researchers and practitioners with an interest in the the role that interaction design and technology can play in wine production and consumption. The outcome of the workshop will be the identification of new opportunities for HCI researchers and practitioners to forge a synergy between technology and wine.

Wine and Interaction Design presents an interesting challenge to the HCI community as technology plays an increasing role in the many facets of wine production and consumption. People interact with technology in all phases of the wine lifecycle, including the grape growing process, harvesting the grapes, supporting the winemaking process, labelling the wine, wine selling, wine serving and wine sharing.

The workshop is aimed at bringing together a group of researchers and practitioners, each with their own knowledge and experience, to share and discuss different theories, methods, designs, or empirical studies that examine connections between wine and interaction design. The workshop involves a full day bus trip visiting locations in northern Tasmania relevant to this topic. Discussions around accepted position papers will take place at different locations during the day. During the field visit, workshop participants will be able to engage with local Tasmanian wine producers, workers and visitors to learn about the context and to inspire ideating on HCI research in enhancing wine-based practices with technology. At the end of the day, the group will collaborate to produce a collection of ideas for future research and practice aimed at forging a synergy between technology and wine.

We invite authors to submit a 2-4 page position paper, in OZCHI paper format, on issues and topics of interest in relation to wine and interaction design. These may or may not be based on empirical studies. These position papers could be specifically about interaction design for wine production or wine consumption, but we are also interested in papers that relate research from other disciplines to digital interactions around wine, wine making, and the human experience of wine. Contributions might include, but are not limited to:

- Understanding the vineyard as a work place

- Understanding social interaction and wine

- Methods for understanding and design in the wine industry

- Design for sharing wine information

- Design for wine appreciation

- Embodied interaction and wine

- Interacting with wine-related technology

- Combining approaches from other disciplines with interaction design and wine
Submissions should be sent in PDF format to jeni@cs.aau.dk. This workshop has limited numbers due to the field visit component.

The workshop organisers are:

Jeni Paay, Associate Professor in the Research Centre for Socio-Interactive Design, Aalborg University, Denmark.

Toni Robertson, Professor of Interaction Design, University of Technology, Sydney.

Margot Brereton, Professor in Computer Human Interaction, Queensland University of Technology, Brisbane.

Yvonne Rogers, Professor of Interaction Design, University College London, UK.

\section{WEBSITE}

For more information about the workshop please visit http://people.cs.aau.dk/ jeni/OZCHIwineworkshop.

\section{REFERENCES}

Brooke, T. and Burrell, J. From Ethnography to Design in a Vineyard. In Proc DUX 2003, ACM (2003), 1-4.

Burrell, J., Brooke, T. and Beckwith, R. Extending Ubiquitous Computing to Vineyards. In Proc. CHI 2003, ACM (2003), 822-xx.

Burrell, J., Brooke, T. and Beckwith, R. Vineyard Computing: Sensor Networks in Agricultural Production. Pervasive Computing x, x (2004), 38-xx.

Chamberlain, A. and Griffiths, C. Wild Food Practices: Understanding the Wider Implications for Design and HCI. In Proc. UbiComp 2013, ACM (2013), 575-xx.

Comber, R., Ganglbaur, E., Choi, J. Hoonhout, J., Rogers, Y., O'Hara, K. and Maitland, J. Food and Interaction Design: Designing for Food in Everyday Lift. In Proc. CHI 2012, ACM (2012), 2767-2770.

Grimes, A. and Harper, R. Celebratory Technology: new directions for food research in HCI. In Proc. CHI 2008, ACM (2008), 467-476.

Kameoka, T., Nsihioka, K., Motonaga, Y., Kimuru, Y., Hashimoto, A. and Wantanabe, N. Smart Sensing in a Vineyard for Advanced Viticultural Management. In Proc. IWWISS'14, ACM (2014), xx-xx.

O’Hara, K., Helmes, J., Bohmer, M., Sellen, A., van den Hoven, E. and Harper, R. Food for Talk: phototalk in the context of sharing a meal. Human Computer Interaction 27, 1-2 (2012)124-150.

Rogers, Y. Moving on From Weiser' Vision of Calm Computing: Engaging UbiComp Experiences. In Proc. Ubicomp 2006, Springer-Verlag (2006), 404-421.

Sherry, J., Mainwaring, S., Burrell, J., Beckwith, R. and Salvador, T. 'This All Together, Hon?" Ubicomp in Non-office Work Environments. In Proc. Ubicomp 2004, Springer-Verlag (2004), 179-195. 